\title{
Full-thickness conjunctival flap covering surgery combined with amniotic membrane transplantation for severe fungal keratitis
}

\author{
JING ZHONG ${ }^{*}$, BOWEN WANG ${ }^{*}$, SAIQUN LI, YUQING DENG, HAIXIANG HUANG, LING CHEN and JIN YUAN \\ State Key Laboratory of Ophthalmology, Zhongshan Ophthalmic Center, \\ Sun Yat-Sen University, Guangzhou, Guangdong 510060, P.R. China
}

Received September 4, 2016; Accepted June 8, 2017

DOI: $10.3892 /$ etm.2018.5765

\begin{abstract}
Fungal keratitis is a severe and common ocular infectious disease. The present study evaluated the efficiency of full-thickness conjunctival flap covering surgery with amniotic membrane transplantation (FCCS + AMT) as a transitional surgery for severe fungal keratitis. A total of 17 patients with severe fungal keratitis without corneal perforation underwent FCCS + AMT between January 2010 and December 2015. The pathogenic factors, preoperative diagnosis and postoperative prognosis of FCCS + AMT at 3 months were evaluated. Subsequently, 7 patients received sclerokeratoplasty, and the best-corrected visual acuity (BCVA) and recurrence ratio were analyzed at 1 month postoperatively. The primary risk factor was agricultural trauma (7 cases), followed by a non-agricultural object entering the eye (3 cases). Preoperatively, there were 10 cases of fungal keratitis positively identified using confocal microscopy and 9 cases positively identified by corneal scrapings. A total of 3 months following FCCS + AMT, the percentage of cases resulting in preservation of the eyeball was $88.24 \%$, with $15 / 17$ patients demonstrating complete conjunctival re-epithelization and a smooth conjunctival surface without any complications. A total of $2(11.76 \%)$ patients experienced melting of the conjunctival flap and development of endophthalmitis, and subsequently underwent ocular evisceration surgery. A total of 7 patients underwent sclerokeratoplasty and the mean logarithm of the minimum angle of resolution BCVA at 1 month was significantly improved $(0.689 \pm 0.121 ; \mathrm{P}<0.001)$ compared with preoperative values $(2.459 \pm 0.037)$ and BCVA values following FCCS + AMT (2.529 \pm 0.066$)$. No recurrence
\end{abstract}

Correspondence to: Dr Jin Yuan, State Key Laboratory of Ophthalmology, Zhongshan Ophthalmic Center, Sun Yat-Sen University, 54 Xianlie Southern Road, Guangzhou, Guangdong 510060, P.R. China

E-mail: yuanjincornea@126.com

*Contributed equally

Key words: fungal keratitis, full-thickness conjunctival flap covering surgery, amniotic membrane transplantation was observed in any of the cases during the follow-up period. Conclusively, FCCS + AMT may be a preferable treatment for severe fungal keratitis of the entire corneal ulcer without perforation, and may save the eyeball and provide a greater opportunity for corneal transplantation.

\section{Introduction}

Fungal keratitis is a severe and common ocular infectious disease that occurs worldwide. This serious condition may threaten visual acuity and cause blindness (1). The prevalence of fungal keratitis has been indicated to be as high as $0.015 \%$, which constituted $61.9 \%$ of severe infective keratitis cases in China $(1,2)$. Clinically, fungal infection slowly and gradually penetrates and deeply infiltrates the cornea (3). Typical clinical features may not be observed during the early stage, which often results in misdiagnosis and a delay in treatment with antifungal medication (3). The antifungal agents used for treatment include polyenes, azoles and fluorinated pyrimidine (4). However, natamycin is considered to be the only commercially available broad-spectrum agent $(5,6)$. Due to the high misdiagnosis rate, the limited number of available antifungal agents and fungal resistance to treatment, it is usually difficult to control the infection (1). In $\sim 1 / 3$ of cases, the fungal infection fails to respond to medical treatment, which may result in a whole cornea ulcer or corneal perforation (7); in these cases, a therapeutic penetrating keratoplasty is necessary (8).

Despite receiving an accurate diagnosis and appropriate treatment, $15-27 \%$ of patients with fungal keratitis require corneal transplantation (9). Although the complexity and difficulty of keratoplasty are considerable disadvantages, the cornea donor shortage is an underlying limitation of this procedure for treating patients with fungal keratitis (10). There is a lack of corneal donation despite the high demand in China, with 200 patients registering for corneal donations and only 60 eyes donated within the past decade, as indicated in a study by Shang and Zhang in 2010 (11). Therefore, transitional surgery, such as conjunctival flap covering surgery, is considered to be another preferable possibility for these patients (12). The technique of using a conjunctival flap for the treatment of chronic corneal ulceration was described by Gundersen (13) in the late 1950s and became a standard surgical procedure. Historically, this procedure has been used for bullous keratopathy, bacterial keratitis, viral keratitis 
and fungal keratitis as a palliative surgery (14-17). The advantages of this surgery are as follows: Corneal inflammation and pain may be well controlled; the flap brings in a blood supply that promotes healing by increasing corneal access to humoral and cellular immune mechanisms; and the procedure is usually cosmetically superior to tarsorrhaphy, and may be performed by the majority of ophthalmologists without sophisticated instrumentation or a need for donor tissue (13). Lingulate, pedicle and bridge flaps have been developed, and the connected flap has been used for whole corneal ulcers that are not perforated (18); however, complications as a result of high tension of the marginal joint, and difficulty in suturing and fixing the cornea typically lead to a cracked conjunctival flap and corneal perforation (18).

In the present study, a novel conjunctival flap covering surgery was developed for treating severe fungal keratitis. Following surgery, 15/17 patients (88.24\%) demonstrated complete conjunctival re-epithelization and a smooth conjunctival surface without any complications.

\section{Patients and methods}

Patients and clinical manifestations. A total of 17 patients ( 1 female and 16 males; age, 50.29 \pm 10.92 years) diagnosed with fungal keratitis and a whole corneal ulcer without perforation were recruited between January 2010 and December 2014 at the Zhongshan Ophthalmic Center, Sun Yat-Sen University (Guangzhou, China). Medical records were reviewed, including age, gender, profession, predisposing associated factors, duration of onset, laboratory tests, best-corrected visual acuity (BCVA), intraocular pressure (IOP) and treatment, and all information was used solely for research purposes. All individuals enrolled in the present study provided written informed consent prior to their inclusion in the study. The present study was approved by the Ethics Committee of the Zhongshan Ophthalmic Center, Sun Yat-Sen University. Furthermore, the study adhered to the tenets of the Declaration of Helsinki.

Diagnosis. The clinical diagnosis of fungal keratitis was based on risk factor analysis, corneal features, confocal microscopy [Heidelberg Retina Tomograph-Rostock Cornea Module (HRT-RCM); Heidelberg Engineering GmBH, Dossenheim, Germany] and corneal cultures of fungi. The criterion used for the identification of fungal filaments on confocal microscopy was the presence of highly reflective, septate, double-walled filaments varying in size between $3-8 \mu \mathrm{m}$ (19). Positivity of fungal growth from corneal-scraping or the presence of fungal filaments on confocal microscopy was considered to indicate fungal keratitis preoperatively. Preoperative B-scan ultrasounds were performed for all patients to exclude endophthalmitis. Postoperatively, the scraped necrotic cornea was divided into several parts for pathological biopsy, hematoxylin and eosin staining and cultures of bacteria and fungi (20). In H\&E staining, Eyes were fixed in $4 \%$ formaldehyde in $0.075 \mathrm{M}$ phosphate buffer for $24 \mathrm{~h}$, dehydrated in increasing concentrations of ethanol (70-99\%) and embedded in paraffin at $60^{\circ} \mathrm{C}$. Sections $5 \mathrm{~mm}$ thick were then cut and floated on deionized water at $45^{\circ} \mathrm{C}$, and single sections were mounted on SuperFrost Plus glass slides (Menzel-Glaser, Braunschweig, Germany). After rehydrating in alcohol (99-70\%) for 3 min in each concentration, all slides were added to the hematoxylin for $4 \mathrm{~min}$ and eosin for $2 \mathrm{~min}$ at $37^{\circ} \mathrm{C}$ and then subsequently dried at $60^{\circ} \mathrm{C}$ for $1 \mathrm{~h}$. All sections were visualized with a Zeiss microscope (Zeiss microscope AXIO Imager A1; Carl Zeiss AG, Oberkochen, Germany) with a magnification of $x 40$. In microculture, Sabouraud and potato dextrose agar were incubated at $25^{\circ} \mathrm{C}$ to enhance the growth of fungi and the media containing blood agar, chocolate agar, brain heart infusion broth and thioglycollate (liquid) for bacteria were incubated at $37^{\circ} \mathrm{C}(20)$.

Indication and exclusion criteria for full-thickness conjunctival flap covering surgery with amniotic membrane transplantation $(F C C S+A M T)$. Preoperatively, all patients were prescribed topically 5\% natamycin eye drops (Alcon, Fort Worth, TX, USA) four times per day, $0.02 \%$ fluconazole eye drops (Zhongshan Ophthalmic Center, Guangzhou, China) every $2 \mathrm{~h}$ daily and $0.02 \%$ fluconazole ointment (Zhongshan Ophthalmic Center) once per night for at least 1 month prior to surgery, combined with $300 \mathrm{mg}$ of voriconazole (Pfizer, New York, NY, USA) taken orally twice daily for at least 2 weeks prior to surgery. Patients who satisfied all of the following indication criteria underwent FCCS + AMT: i) Poor response to topical therapy; ii) an increasingly large lesion involving the entire cornea; iii) gradual thinning of the cornea with no observable perforation by fluorescein staining; and iv) no endophthalmitis according to B-scan ultrasounds. Patients meeting any of the following criteria were excluded from FCCS + AMT: i) Corneal perforation was present; ii) endophthalmitis was detected by B-scan ultrasound; iii) hypopyon was present in the eye; and iv) treatment with antifungal medication was effective.

Surgical technique. All surgeries in the present study were performed by the same surgeon. A trephine with a diameter of $11 \mathrm{~mm}$ and a marker pen were used to mark the margin of the conjunctival flap. Subsequently, a full-thickness conjunctival flap with Tenon's capsule was dissected and the suppurative and necrotic cornea was removed. A regular and smooth surface was cut using a corneal shaper and cornea fixation forceps to assure the complete attachment of the conjunctival flap. The conjunctival flap was secured to the cornea with interrupted 10-0 nylon sutures, and fixed with the limbal and episcleral tissue of the cornea peripherally to avoid a conjunctival flap crack or a deficiency of limbal stem cells postoperatively. The donor bed was transplanted with the cryopreserved amniotic membrane once thawed, and washed with phosphate-buffered saline (PBS) in a $20 \mathrm{ml}$ culture dish for 3-5 min with the stromal side facing down to accelerate conjunctival epithelial migration (Fig. 1). The amniotic membrane was obtained from the Eye Bank of Guangdong Province (Guangzhou, China), which was acquired from caesarean deliveries, and was previously confirmed negative of hepatitis B and C virus or human immunodeficiency virus. The membrane was prepared and stored sterilely according to previously reported methods (21). Following surgery, the removed tissue was cut into $2 \mu \mathrm{m}$ pieces for histopathology and fungal cultures (22). Fig. 2 indicated the flow chart 
A

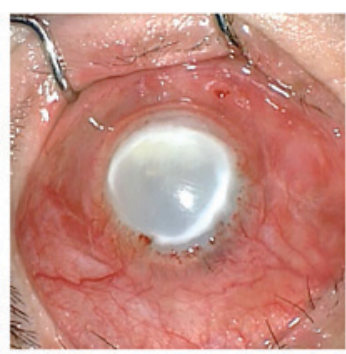

E

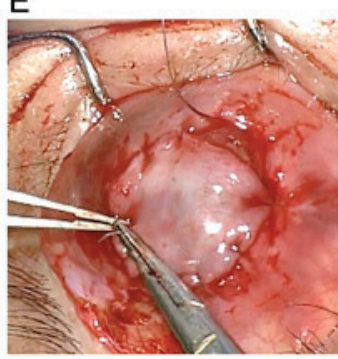

B

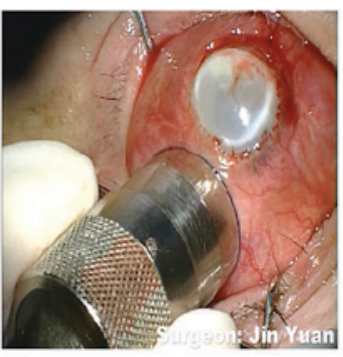

F

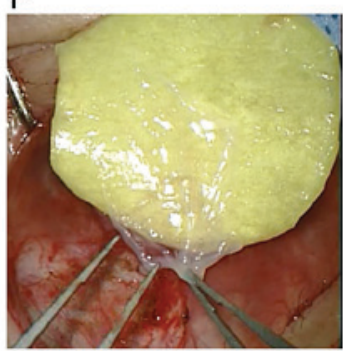

C

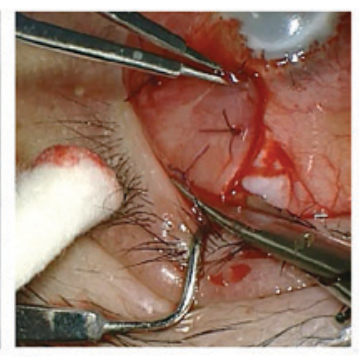

G

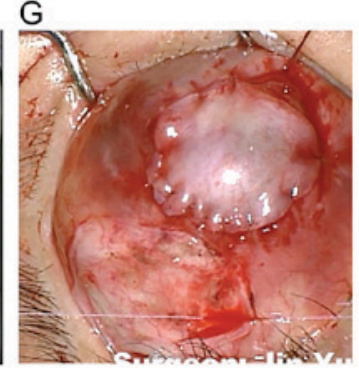

$\mathrm{D}$

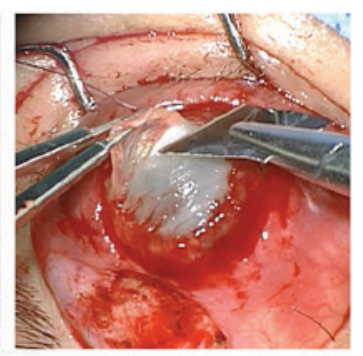

$\mathrm{H}$

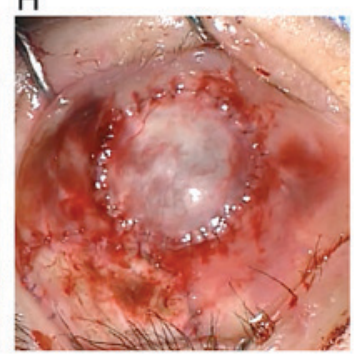

Figure 1. Intraoperative view. (A) Fungal keratitis; (B) the margin of the conjunctival flap was marked using a trephine; (C) the full-thickness free conjunctival flap was incised; (D) the necrotic cornea was sliced to provide a regular and smooth surface; (E) the conjunctival flap was secured with limbal and episcleral tissue of the cornea peripherally; (F) the amniotic membrane was transplanted; $(\mathrm{G})$ the total conjunctival flap covered the cornea. (H) Postoperative ocular surface image.

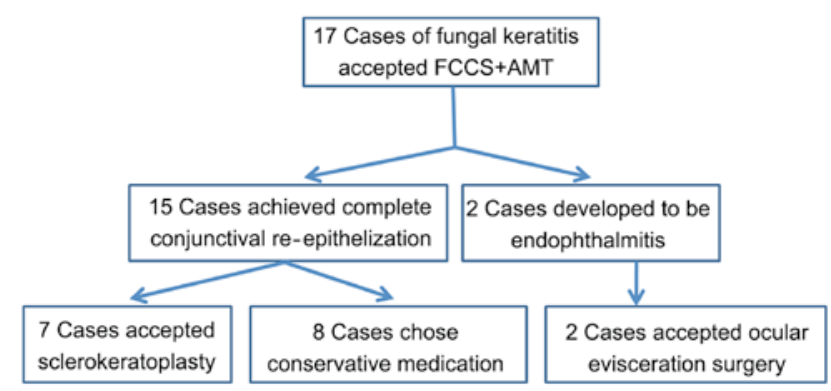

Figure 2. Flow chart displaying the specific treatment in different patients with fungal keratitis following FCCS + AMT. FCCS + AMT, full-thickness conjunctival flap covering surgery with amniotic membrane transplantation.

displaying the specific treatments different patients with fungal keratitis received following FCCS + AMT.

Postoperative treatment and follow-up. Following FCCS + AMT, all patients were prescribed the following antifungal agents: Topical 5\% natamycin; $0.02 \%$ fluconazole eye drops every $2 \mathrm{~h}$ daily; and $0.02 \%$ fluconazole ointment once per night combined with $300 \mathrm{mg}$ of voriconazole for at least 1 month] and were examined once a month for 3 months. 2 patients developed endophthalmitis with a melted conjunctival flap and accepted ocular enucleation surgery, whereas 7/15 remaining patients who satisfied all of the following criteria received routine sclerokeratoplasty: i) The conjunctival flap did not melt; ii) severe conjunctival congestion or edema did not occur; and iii) visual acuity was not less than light perception. The other 8 patients chose the following conservative medication: Topical 5\% natamycin eye drops four times per day, $0.02 \%$ fluconazole eye drops every $2 \mathrm{~h}$ daily and $0.02 \%$ fluconazole ointment once per night, combined with $300 \mathrm{mg}$ or 4-6 mg/Kg of voriconazole orally for 3 months after FCCS + AMT immediately due to economic reasons.

Following corneal transplantation, anti-inflammatory and anti-infectious agents (topically 5\% natamycin eye drops four times per day, $0.2 \%$ fluconazole eye drops every $2 \mathrm{~h}$ daily, and $0.5 \%$ fluconazole ointment once per night, combined with $300 \mathrm{mg}$ or $4-6 \mathrm{mg} / \mathrm{Kg}$ of voriconazole orally for 3 months due to economic reasons) were prescribed for at least 1 month immediately following transplantation, combined with $0.05 \%$ tacrolimus (FK506) eyedrops three times a day (Zhongshan Ophthalmic Center) for at least 1 year to prevent recurrence and graft rejection.

Following sclerokeratoplasty, the following indices were evaluated at months 1, 6 and 12: BCVA by visual chart; IOP by the ocular palpation method where index fingers of both hands are placed on the top of the eyelid, over the cartilage and pressing the eyeball alternately with one or another finger the doctor may feel fluctuations (23); and graft transparency and recurrence rate in which graft failure was defined as an irreversible loss of graft clarity resulting from any cause, including persistent epithelial defects, nonendothelial graft rejection, or interface opacity/vascularization (20). For the ocular palpation method, $\mathrm{Tn}=\mathrm{regular}$ intraocular pressure; $\mathrm{T}+1=$ slightly increased intraocular pressure; $\mathrm{T}+2=$ rigid eyeball; $\mathrm{T}+3=$ hard eyeball, hard as rock; T-1=slightly softer eyeball; T-2=soft eyeball; T-3=very soft eyeball (23). Snellen visual acuity was recorded and approximations for visual acuity worse than 20/400 were determined considering the following: Counting fingers $=20 / 2,000$, hand motions $=20 / 4,000$, light perception $=20 / 8,000$, and no light perception=20/16,000. Snellen vision was converted to $\log$ MAR values for statistical analysis (24). IOP and BCVA were also evaluated in patients that did not receive this surgery at months 1, 6 and 12 following conservative medication (Table II). 
Table I. Clinical features and clinical examination.

Preoperative

\begin{tabular}{|c|c|c|c|c|c|c|}
\hline \multirow[b]{2}{*}{ Case no. } & \multirow[b]{2}{*}{ Risk factor } & \multirow[b]{2}{*}{$\begin{array}{c}\text { Duration of } \\
\text { disease, month }\end{array}$} & \multirow[b]{2}{*}{$\begin{array}{l}\text { Diameter of } \\
\text { lesion, } \mathrm{mm}\end{array}$} & & \multirow[b]{2}{*}{$\begin{array}{l}\text { Postoperative } \\
\text { corneal-scraping culture }\end{array}$} \\
\hline & & & & Confocal scan & $\begin{array}{c}\text { Corneal-scraping } \\
\text { culture }\end{array}$ & \\
\hline P1 & $\begin{array}{l}\text { Agricultural } \\
\text { trauma }\end{array}$ & 2 & 9 & Fungal hyphae & Fusarium solani & Fusarium solani \\
\hline P2 & $\begin{array}{l}\text { Agricultural } \\
\text { trauma }\end{array}$ & 1 & 10 & Fungal hyphae & - & - \\
\hline P3 & $\begin{array}{l}\text { Agricultural } \\
\text { trauma }\end{array}$ & 1 & 10 & - & Fusarium solani & Fusarium solani \\
\hline P4 & $\begin{array}{l}\text { Iron wire } \\
\text { hitting }\end{array}$ & 1.5 & 7 & Fungal hyphae & - & Fusarium solani \\
\hline P5 & Unclear & 2 & 10 & Fungal hyphae & - & - \\
\hline P6 & $\begin{array}{l}\text { Chalk entering } \\
\text { eye }\end{array}$ & 21 & 6 & - & $\begin{array}{l}\text { Aspergillus } \\
\text { fumigatus }\end{array}$ & $\begin{array}{l}\text { Aspergillus } \\
\text { fumigatus }\end{array}$ \\
\hline P7 & $\begin{array}{l}\text { Agricultural } \\
\text { trauma }\end{array}$ & 3 & 10 & - & $\begin{array}{l}\text { Aspergillus } \\
\text { fumigatus }\end{array}$ & $\begin{array}{l}\text { Aspergillus } \\
\text { fumigatus }\end{array}$ \\
\hline P8 & Unclear & 1 & 8 & - & Fusarium solani & Fusarium solani \\
\hline P9 & Unclear & 2 & 8 & Fungal hyphae & - & $\begin{array}{l}\text { Grasses } \\
\text { helminthosporium }\end{array}$ \\
\hline $\mathrm{P} 10$ & $\begin{array}{l}\text { Agricultural } \\
\text { trauma }\end{array}$ & 1 & 9 & Fungal hyphae & - & Aspergillus flavus \\
\hline P11 & Unclear & 1 & 8 & Fungal hyphae & - & Mucor \\
\hline $\mathrm{P} 12$ & Unclear & 1 & 6 & - & Penicillium & Penicillium \\
\hline $\mathrm{P} 13$ & $\begin{array}{l}\text { Agricultural } \\
\text { trauma }\end{array}$ & 2 & 6 & Fungal hyphae & Fusarium solani & Fusarium solani \\
\hline P14 & $\begin{array}{l}\text { Pepper sauce } \\
\text { entering eye }\end{array}$ & 0.5 & 5 & - & Curvularia & Curvularia \\
\hline P15 & $\begin{array}{l}\text { Insects entering } \\
\text { eye }\end{array}$ & 1 & 5 & - & Fusarium solani & Fusarium solani \\
\hline P16 & $\begin{array}{l}\text { Agricultural } \\
\text { trauma }\end{array}$ & 1 & 6 & Fungal hyphae & - & Aspergillus flavus \\
\hline P17 & Unclear & 1 & 8 & Fungal hyphae & - & Cephalosporium \\
\hline
\end{tabular}

Statistical analysis. SPSS software version 13.0 (SPSS, Inc., Chicago, IL, USA) was used for the statistical analysis. Data were presented as the mean \pm standard error of the mean. An unpaired, two-tailed Student's t-test was used to determine the statistical significance of BCVA preoperatively and postoperatively. $\mathrm{P}<0.05$ was considered to indicate a statistically significant difference.

\section{Results}

Clinical data and clinical features. A total of 17 eyes from 17 patients were included in the present study. From the total 17 patients, 16 patients $(94.12 \%)$ were male and 1 patient (5.88\%) was female. The mean age was $50.29 \pm 10.92$ (30-72) years. A total of 11 affected eyes $(64.71 \%)$ were right eyes and $6(35.29 \%)$ were left eyes. Of the 17 patients, the mean disease duration was $2.53 \pm 4.66(0.5-21)$ months and the mean diameter of the lesion was $7.71 \pm 1.74(5-10) \mathrm{mm}$. A total of $13(76.47 \%)$ patients were farmers; 7 patients experienced agricultural trauma; 3 patients had a history of a non-agricultural body entering the eye; 1 patient was hit by an iron wire; and the other 6 patients had unclear predisposing factors (Table I).

No cases exhibited perforation preoperatively. Although these patients exhibited nonspecific clinical signs, including blurred vision, redness, tearing, photophobia, pain, foreign body sensation and secretions in the late stage of fungal keratitis with a whole corneal ulcer, some typical signs, including a dry and rough corneal surface (10/15 patients), an irregular feathery-edged infiltrate ( $8 / 15$ patients), a white ring in the cornea and a satellite lesion (7/15 patients), were also observed. Preoperatively, the mean LogMAR BCVA was $2.459 \pm 0.037$. A total of 3 patients exhibited high IOP ( $\mathrm{T}+1$ and $\mathrm{T}+2), 6$ patients had low IOP (T-1 and T-2) and the remaining 8 patients had normal IOP (Tn) (Table II).

Confocal microscopy and microbiology. Prior to FCCS + AMT, fungal hyphae were identified in 10 cases (58.82\%) by confocal microscopy, and corneal scrapings 
Table II. BCVA and IOP of patients.

\begin{tabular}{|c|c|c|c|c|c|c|}
\hline $\begin{array}{l}\text { Case } \\
\text { no. }\end{array}$ & $\begin{array}{l}\text { Preoperative } \\
\text { BCVA }\end{array}$ & $\begin{array}{c}\text { Preoperative } \\
\text { IOP }\end{array}$ & $\begin{array}{c}\text { BCVA } \\
\text { following } \\
\text { FCCS + AMT }\end{array}$ & $\begin{array}{c}\text { IOP } \\
\text { following } \\
\text { FCCS + AMT }\end{array}$ & $\begin{array}{l}\text { BCVA following } \\
\text { sclerokeratoplasty/ } \\
\text { conservative } \\
\text { medication }\end{array}$ & $\begin{array}{l}\text { IOP following } \\
\text { sclerokeratoplasty/ } \\
\text { conservative } \\
\text { medication }\end{array}$ \\
\hline $\mathrm{P} 1$ & 2.60 & $\operatorname{Tn}$ & 2.30 & $\operatorname{Tn}$ & 1.00 & $\operatorname{Tn}$ \\
\hline $\mathrm{P} 2$ & 2.60 & $\mathrm{~T}-1$ & 2.30 & Tn & 0.52 & Tn \\
\hline P3 & 2.60 & $\mathrm{~T}+1$ & 2.90 & $\mathrm{Tn}$ & 0.30 & $\mathrm{Tn}$ \\
\hline $\mathrm{P} 4$ & 2.30 & Tn & 2.30 & $\mathrm{Tn}$ & 2.30 & $\operatorname{Tn}$ \\
\hline P5 & 2.60 & Tn & 2.60 & Tn & 2.60 & $\mathrm{Tn}$ \\
\hline P6 & 2.30 & T-1 & 2.30 & $\mathrm{~T}-1$ & $\begin{array}{l}\text { Flap melting and } \\
\text { corneal perforation }\end{array}$ & $\mathrm{Tn}$ \\
\hline P7 & 2.30 & $\mathrm{~T}-1$ & 2.00 & $\mathrm{~T}-1$ & $\begin{array}{l}\text { Flap melting and } \\
\text { corneal perforation }\end{array}$ & Tn \\
\hline P8 & 2.60 & $\mathrm{Tn}$ & 2.60 & $\mathrm{Tn}$ & 2.60 & $\mathrm{Tn}$ \\
\hline P9 & 2.60 & T-1 & 2.90 & $\mathrm{Tn}$ & 2.90 & $\mathrm{Tn}$ \\
\hline P10 & 2.60 & T-2 & 2.60 & $\mathrm{Tn}$ & 2.60 & $\operatorname{Tn}$ \\
\hline P11 & 2.60 & $\operatorname{Tn}$ & 2.60 & $\mathrm{Tn}$ & 1.00 & $\mathrm{Tn}$ \\
\hline P12 & 2.30 & Tn & 2.90 & $\operatorname{Tn}$ & 2.90 & $\operatorname{Tn}$ \\
\hline P13 & 2.60 & Tn & 2.30 & Tn & 0.30 & $\mathrm{Tn}$ \\
\hline P14 & 2.30 & $\mathrm{~T}+2$ & 2.90 & Tn & 2.90 & $\mathrm{Tn}$ \\
\hline P15 & 2.30 & $\mathrm{~T}+1$ & 2.60 & $\mathrm{Tn}$ & 1.00 & $\operatorname{Tn}$ \\
\hline P16 & 2.30 & $\mathrm{~T}-1$ & 2.30 & Tn & 0.70 & Tn \\
\hline P17 & 2.30 & $\mathrm{Tn}$ & 2.60 & Tn & 2.60 & Tn \\
\hline
\end{tabular}

P, patient; BCVA, best-corrected visual acuity; IOP, intraocular pressure; FCCS + AMT, full-thickness conjunctival flap covering surgery with amniotic membrane transplantation. High intraocular pressure: T+1 or T+2; Low intraocular pressure: T-1 or T-2; Normal intraocular pressure: Tn.

indicated that 9 cases $(52.94 \%)$ had positive culture results, corresponding to 5 cases of Fusarium solani, 2 cases of Aspergillus fumigatus, 1 case of Curvularia and 1 case of Penicillium (Table I).

Following FCCS + AMT, positive histopathology and culture results were revealed in 15 patients $(88.24 \%)$, including 6 cases of $F$. solani, 2 cases of A.fumigatus, 2 cases of A. flavus, 1 case of Grasses helminthosporium, 1 case of Mucor, 1 case of Penicillium, 1 case of Curvularia and 1 case of Cephalosporium, representing 6 further cases of positive culture results compared with those observed preoperatively (Table I). The 2 negative-culture cases had positive confocal scan results preoperatively.

Prognosis following FCCS + AMT. Following FCCS + AMT, 15 patients $(88.24 \%)$ achieved complete conjunctival reepithelization, a vascularized flap with no inflammation, and a smooth conjunctival surface, whereas 2 patients (P6 and 7) developed endophthalmitis with a melted conjunctival flap and corneal perforation at 1 and 2 weeks following FCCS + AMT surgery. Both of these patients underwent ocular evisceration surgery. The rate of eyeball preservation was $88.24 \%$. No notable improvement in BCVA $(2.529 \pm 0.066)$ was observed compared with the preoperative status. IOP was normal in 15 cases (88.24\%), as assessed by the ocular palpation method (23), and the other 2 patients who experienced a melted flap had low
IOP (Table II). No other complications were encountered in the present study.

Preoperative and postoperative slit-lamp images were indicated in Fig. 3. Fig. 3A, C and E demonstrate 3 cases (patient 1, 2 and 3, respectively) with a conjunctival infection, a large corneal fungal abscess (lesion diameters were 9, 10 and $10 \mathrm{~mm}$, respectively) without perforation and vision with full light perception preoperatively. At 1 week following FCCS + AMT (Fig. 3B), the conjunctival flap was fixed tightly with the corneal limbal tissue, flap edema was observed and some neovascularization began to appear on the peripheral side. At 2 weeks postoperatively, flap edema was alleviated, the absorbable suture was absorbed and the peripheral side was smoother when the flap had begun to connect with the ulcerated cornea (Fig. 3D). At 1 month postoperatively, ocular surface vascularization and complete conjunctival re-epithelization was observed, a non-conjunctival inflammatory $y$ reaction was noted and the conjunctival margins showed stable scarring (Fig. 3F). Fig. 3B, D and F depicted the healing process of the conjunctival flap from 1 week to 2 weeks and 1 month postoperatively.

Prognosis following sclerokeratoplasty surgery. A total of 3 months following FCCS + AMT, 7 patients satisfied the indication criteria and accepted sclerokeratoplasty and 8 chose conservative medication due to economic reasons. 


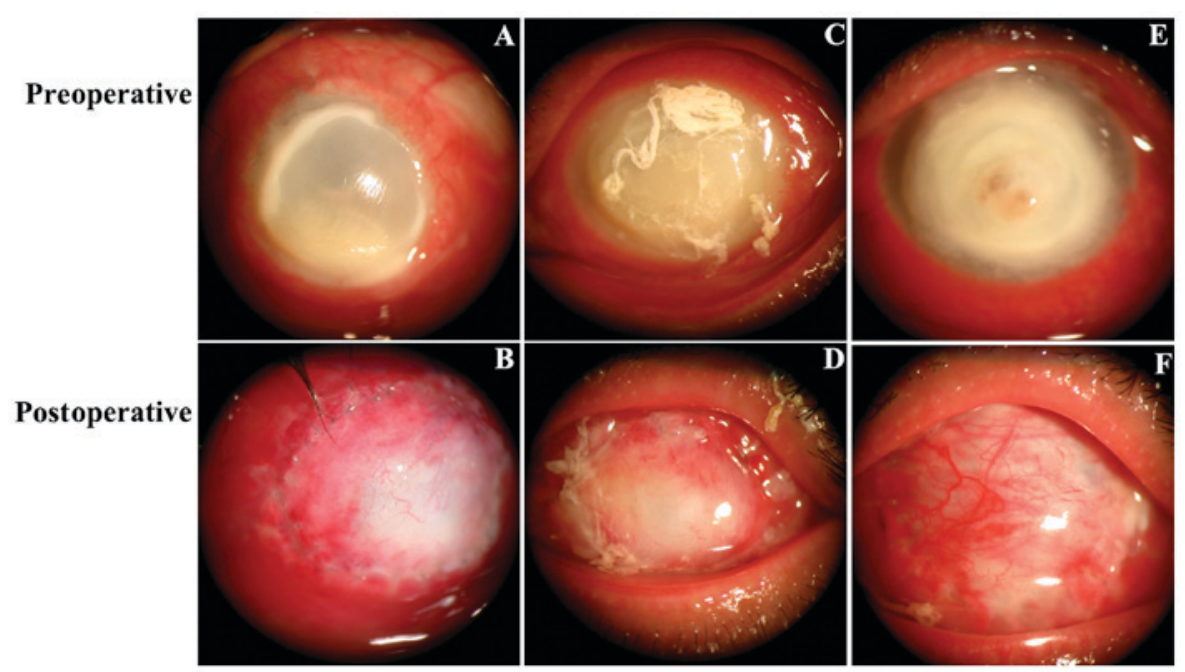

Figure 3. Preoperative and postoperative slit-lamp images. (A-C) Preoperative slit-lamp photographs of patients. (D) At 1 week following FCCS + AMT, neovascularization was initially observed on the peripheral side of the conjunctival flap. (E) At 2 weeks following FCCS + AMT, the peripheral side of the flap was smoother and the flap had begun to bond with the ulcerative cornea. (F) At 1 month following FCCS + AMT, the conjunctival margin demonstrated stable scarring. FCCS + AMT, full-thickness conjunctival flap covering surgery with amniotic membrane transplantation.

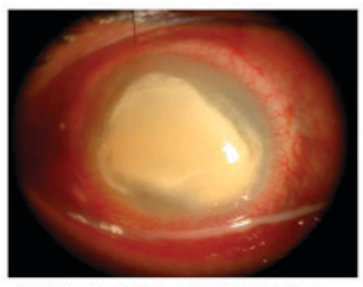

A: Preoperative photography

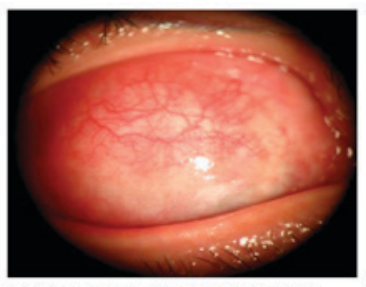

B: $3 \mathrm{M}$ following FCCS+AMT

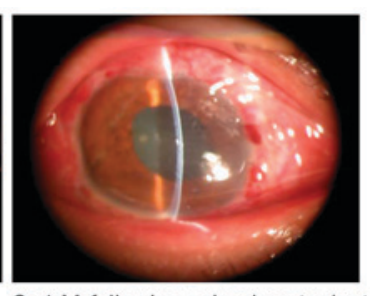

$\mathrm{C}: 1 \mathrm{M}$ following sclerokeratoplasty

Figure 4. Therapeutic process. (A) Preoperative image. (B) At $3 \mathrm{M}$ after FCCS + AMT, the vascularized conjunctival flap and smooth conjunctival surface were visible. (C) At $1 \mathrm{M}$ following sclerokeratoplasty surgery. FCCS + AMT, full-thickness conjunctival flap covering surgery with amniotic membrane transplantation; M, month.

All patients were followed up for at least 1 month, and no patients experienced fungal recurrence or graft rejection. The entire therapeutic process for 1 case, from preoperative stage to 3 months following FCCS + AMT and 1 month following sclerokeratoplasty is demonstrated in Fig. 4. The graft remained clear through the last follow-up visit. The mean LogMAR BCVA in the 7 patients at 1 month following sclerokeratoplasty demonstrated significant improvement $(0.689 \pm 0.121)$ compared with preoperative values $(2.459 \pm 0.037 ; \mathrm{P}<0.01)$; similarly, this improvement was also observed when compared with the BCVA values at 3 months following FCCS + AMT (2.529 $\pm 0.066 ; \mathrm{P}<0.001$; Fig. 5). The mean LogMAR BCVA in the 8 patients who accepted conservative medication was similar to that at 3 months following FCCS + AMT (Table II) Furthermore, the IOP for all the patients (via the ocular palpation method) was normal following sclerokeratoplasty or conservative medication (Table II).

\section{Discussion}

Fungal keratitis is challenging to overcome as the incidence has increased, there are a limited number of effective antifungal agents and there is a shortage of cornea donors for keratoplasty (4). The perforation rate is high, particularly when whole corneal ulcers develop during the late stage (25).

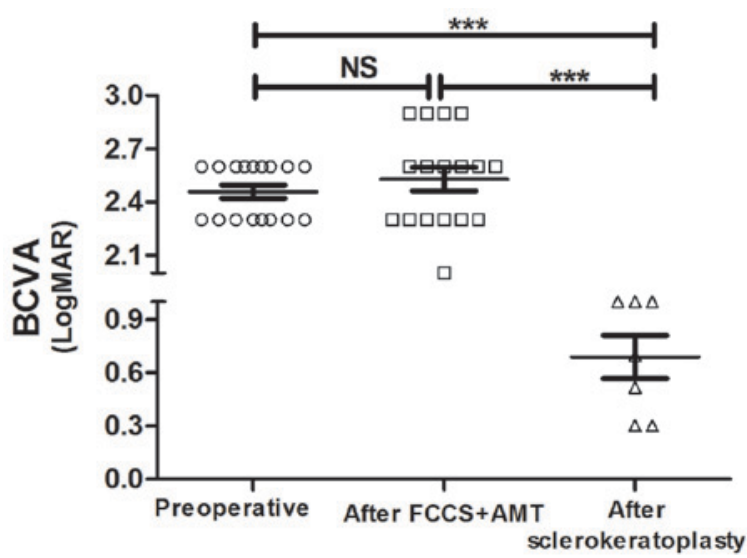

Figure 5. LogMAR BCVA of the patients at the preoperative stage compared with those who had received FCCS + AMT and sclerokeratoplasty. Data are presented as the mean \pm standard error of the mean. ${ }^{*} \mathrm{P}<0.05 ;{ }^{* *} \mathrm{P}<0.01$; ${ }^{* * *} \mathrm{P}<0.001$. BCVA, best-corrected visual acuity; FCCS + AMT, full-thickness conjunctival flap covering surgery with amniotic membrane transplantation; ns, not significant.

Furthermore, corneal surgery will not repair vision and results in a poor prognosis in severe cases of fungal keratitis (26). Thus, early diagnosis coupled with appropriate treatment is critical (27). 
Despite ophthalmologists' best efforts, medical treatment fails in $15-36 \%$ of cases $(6,28)$. When this occurs, therapeutic keratoplasty is necessary (29). However, there is a large discrepancy between the supply and demand of transplantable organs, despite the existence of sufficient numbers of potential donors (30). Particularly in developing countries, the shortage of cornea donors is as high as 52\% (10). Therefore, transitional surgeries, including simple debridement, excisional keratectomy, amniotic membrane transplantation and conjunctival flap covering surgery, have an important role in inhibiting disease progression (27).

Surgical debridement may create a smoother surface for a superficial lesion and promote rapid healing and re-epithelialization of the cornea; however, it is rarely successful in severe cases without further surgery and does not reduce the recurrence of infectious keratitis (31). Amniotic membrane transplantation may be used as a temporary patch or a permanent graft to promote healing and decrease inflammation and scarring, but it is not feasible if the area to be treated is large and the ratio of dissolution is relatively high in severe fungal keratitis cases presenting with a whole corneal ulcer (32). Conjunctival flaps have been used to halt the progression of refractory corneal abscesses, which are resistant to medical therapy (23). The flaps provide structural support for necrotic tissue and are able to control the infection and maintain the integrity of the globe (33). A study by Abdulhalim et al (33) reported the conditions of 20 eyes from 20 patients who underwent bipedicle conjunctival flap covering surgery as follows: A total of 12 eyes had fungal keratitis, 7 eyes had bacterial keratitis and 1 eye had Acanthamoeba keratitis. When considering fungal keratitis with deep stromal infiltration, a thick flap with Tenon's capsule increased the resistance to infection and provided stronger mechanical support for the cornea (27). Previously, conjunctival flap covering surgery had not been successful in cases of active fungal corneal ulcers resistant to topical and systemic antifungal agents (23). The most frequently reported complications include flap retraction, conjunctival buttonholes and corneal perforations (34). A study by Alino et al (34) indicated that the retraction of a partial flap is likely to be affected by gravity and blinking action, and the edge of the partial flap is close to the edge of the defect, which does not provide enough tension. A study by Sun et al (18) suggested that the major reason for the failure is incomplete removal of necrotic tissue, which may lead to a high incidence of corneal perforation. Therefore, in the present study, the suppurative and necrotic corneas were removed initially, followed by suturing of a full-thickness conjunctival flap with Tenon's capsule to the corneal limbal and episcleral tissue peripherally in a 360-degree manner to increase flap tension. Furthermore, the donor bed was transplanted with the amniotic membrane to achieve rapid wound healing.

In the present study, $15 / 17$ patients $(88.24 \%)$ demonstrated complete conjunctival re-epithelization and a smooth conjunctival surface at 3 months postoperatively. Unlike the studies by Khodadoust and Quinter (35) and Abdulhalim et al (33), no patient experienced conjunctival retraction or recession of the flap and no other complications occurred in the present study. We deduced that the advantages of the technique in the present study were the intact conjunctival flap, fixed margin and strong mechanical support. However, 2 patients experienced conjunctival flap melting accompanied by corneal perforation. We suspected that the fungal toxicity of Aspergillus fumigatus in these 2 patients was high and that the invasiveness was relatively potent. Additionally, the duration of disease was 21 and 3 months, respectively, which corresponded to the late stage of fungal keratitis. The long duration may have delayed the timely medical and surgical intervention. Thus, prompt and early diagnosis and surgery is crucial.

The present findings suggested that FCCS + AMT may be a beneficial choice for promoting wound healing and creating a greater opportunity for possible corneal transplantation. The full-thickness conjunctival flap is rich in blood vessels and lymphatics, which are necessary to transport nutrients to the corneal surface to help resist infection and provide strong mechanical support (23). Additionally, the rich blood supply decreases proinflammatory mediators and proteases in the microenvironment (23) and the immune modulator wash-out further decreases the inflammation and aids the healing of refractory corneal ulcers (36). Furthermore, the amniotic membrane decreases vascularization and promotes conjunctival donor healing (32). However, in-depth discussion concerning FCCS + AMT is required if corneal perforation is present, particularly when the hole is large. The present results indicated that 7 patients underwent sclerokeratoplasty surgery and their visual acuity significantly increased in comparison with the visual acuity preoperatively; the other 8 patients refused surgery and chose conservative medication due to economic reasons.

The limitations of the present technique include a lack of controls and the small sample size. For whole corneal ulcers in severe fungal keratitis, corneal transplantation is considered to be an optimal surgery to restore ocular integrity and FCCS + AMT may be a preferable second choice. In conclusion, FCCS + AMT may provide a greater opportunity for corneal transplantation, which may improve the prognosis for patients with fungal keratitis.

\section{Acknowledgements}

The authors would like to thank all the professors and nurses in the Cornea Department of Zhongshan Ophthalmic Center (Guangzhou, China). The present study was supported by a grant from the National Natural Science Foundation of China, received by J.Y. (grant no. 81270972).

\section{References}

1. Cao J, Yang Y, Yang W, Wu R, Xiao X, Yuan J, Xing Y and Tan X: Prevalence of infectious keratitis in Central China. BMC Ophthalmol 14: 43, 2014.

2. Xie L, Zhong W, Shi W and Sun S: Spectrum of fungal keratitis in north China. Ophthalmology 113: 1943-1948, 2006.

3. Thomas PA: Fungal infections of the cornea. Eye (Lond) 17: 852-862, 2003.

4. FlorCruz NV and Evans JR: Medical interventions for fungal keratitis. Cochrane Database Syst Rev 4: CD004241, 2015.

5. Prajna NV, Krishnan T, Mascarenhas J, Rajaraman R, Prajna L, Srinivasan M, Raghavan A, Oldenburg CE, Ray KJ, Zegans ME, et al: The mycotic ulcer treatment trial: a randomized trial comparing natamycin vs voriconazole. JAMA Ophthalmol 131: 422-429, 2013. 
6. Prajna NV, Mascarenhas J, Krishnan T, Reddy PR, Prajna L, Srinivasan M, Vaitilingam CM, Hong KC, Lee SM, McLeod SD, et al: Comparison of natamycin and voriconazole for the treatment of fungal keratitis. Arch Ophthalmol 128: 672-678, 2010.

7. Prajna NV, Krishnan T, Mascarenhas J, Srinivasan M, Oldenburg CE, Toutain-Kidd CM, Sy A, McLeod SD, Zegans ME Acharya NR, et al: Predictors of outcome in fungal keratitis. Eye (Lond) 26: 1226-1231, 2012.

8. Li LM, Zhao LQ, Qu LH and Li P: Excimer laser phototherapeutic keratectomy for the treatment of clinically presumed fungal keratitis. J Ophthalmol 2014: 963287, 2014.

9. Henry CR, Flynn HW Jr, Miller D, Schefler AC, Forster RK and Alfonso EC: Delayed-onset endophthalmitis associated with corneal suture infections. J Ophthalmic Inflamm Infect 3: 51, 2013.

10. Jiaxu Hong, Weiyun Shi, Zuguo Liu, Roberto Pineda, Xinhan Cui, Xinghuai Sun and Jianjiang Xu: Limitations of Keratoplasty in China: A Survey Analysis. PLoS One 10 e0132268, 2015

11. Shang $X$ and Zhang M: Body and organ donation in Wuhan, China. Lancet 376: 1033-1034, 2010.

12. Sharma A, Mohan K, Sharma R and Nirankari VS: Repositioning of pedicle conjunctival flap performed for refractory corneal ulcer. Middle East Afr J Ophthalmol 21: 89-91, 2014.

13. Gundersen T: Conjunctival flaps in the treatment of corneal disease with reference to a new technique of application. AMA Arch Ophthalmol 60: 880-888, 1958.

14. Gao H, Jia Y, Li S, Wang T, Tan Y and Shi W: Conjunctival flap covering combined with antiviral and steroid therapy for severe herpes simplex virus necrotizing stromal keratitis. Scientific World Journal 2015: 565964, 2015.

15. Yang X, Zhou Q and Du S: Conjunctival flap covering in the treatment of corneal blood staining. Can J Ophthalmol 46 : 442-443, 2011.

16. Ding J, Chen T, Hou Z, Qin Y, Hao L and Li D: Cosmetic shell fitting over a sensitive cornea in mild phthisis bulbi using total conjunctival flap. Aesthetic Plast Surg 37: 398-401, 2013.

17. Yazici B: Use of conjunctiva-Muller muscle pedicle flap in surgical treatment of necrotizing scleritis. Ophthal Plast Reconstr Surg 24: 19-23, 2008.

18. Sun GH, Li SX, Gao H, Zhang WB, Zhang MA and Shi WY: Clinical observation of removal of the necrotic corneal tissue combined with conjunctival flap covering surgery under the guidance of the AS-OCT in treatment of fungal keratitis. Int J Ophthalmol 5: 88-91, 2012.

19. Erie JC, McLaren JW and Patel SV: Confocal microscopy in ophthalmology. Am J Ophthalmol 148: 639-646, 2009.

20. Cruciani F, Cuozzo G, Di Pillo S and Cavallaro M: Predisposing factors, clinical and microbiological aspects of bacterial keratitis: A clinical study. Clin Ter 160: 207-210, 2009
21. Kim JC and Tseng SC: Transplantation of preserved human amniotic membrane for surface reconstruction in severely damaged rabbit corneas. Cornea 14: 473-484, 1995.

22. Gopinathan U, Garg P, Fernandes M, Sharma S, Athmanathan S and Rao GN: The epidemiological features and laboratory results of fungal keratitis: A 10-year review at a referral eye care center in South India. Cornea 21: 555-559, 2002.

23. Baum J, Chaturvedi N, Netland PA and Dreyer EB: Assessment of intraocular pressure by palpation. Am J Ophthalmol 119: 650-651, 1995.

24. The ischemic optic neuropathy decompression trial (IONDT): design and methods. Control Clin Trials 19: 276-296, 1998.

25. Arbelaez JG, Feng MT, Pena TJ, Price MO and Price FW Jr: A year of cornea in review: 2013. Asia Pac J Ophthalmol (Phila) 4: 40-50, 2015.

26. Avunduk AM, Beuerman RW, Varnell ED and Kaufman HE: Confocal microscopy of Aspergillus fumigatus keratitis. $\mathrm{Br}$ J Ophthalmol 87: 409-410, 2003.

27. Eguchi H, Toibana T, Hotta F, Miyamoto T, Mitamura Y and Yaguchi T: Severe fungal sclerokeratitis caused by Metarhizium anisopliae: A case report and literature review. Mycoses 58: 88-92, 2015.

28. Anane S, Ben Ayed N, Malek I, Chebbi A, Lejri S, Bouguila H, Kaouech E, Belhadj S, Kallel K, Ayed S and Chaker E: Keratomycosis in the area of Tunis: epidemiological data, diagnostic and therapeutic modalities. Ann Biol Clin (Paris) 68: 441-447, 2010 (In French).

29. Yao YF, Zhang YM, Zhou P, Zhang B, Qiu WY and Tseng SC: Therapeutic penetrating keratoplasty in severe fungal keratitis using cryopreserved donor corneas. Br J Ophthalmol 87: 543-547, 2003.

30. Golchet G, Carr J and Harris MG: Why don't we have enough cornea donors? A literature review and survey. Optometry 71: 318-328, 2000.

31. Ozbek Z, Burakgazi AZ and Rapuano CJ: Rapid healing of vernal shield ulcer after surgical debridement: A case report. Cornea 25: 472-473, 2006

32. Liu J, Sheha H, Fu Y, Liang L and Tseng SC: Update on amniotic membrane transplantation. Expert Rev Ophthalmol 5: 645-661, 2010.

33. Abdulhalim BE, Wagih MM, Gad AA, Boghdadi G and Nagy RR: Amniotic membrane graft to conjunctival flap in treatment of non-viral resistant infectious keratitis: a randomised clinical study. Br J Ophthalmol 99: 59-63, 2015.

34. Alino AM, Perry HD, Kanellopoulos AJ, Donnenfeld ED and Rahn EK: Conjunctival flaps. Ophthalmology 105: 1120-1123, 1998.

35. Khodadoust A and Quinter AP: Microsurgical approach to the conjunctival flap. Arch Ophthalmol 121: 1189-1193, 2003.

36. Zhou Q, Long X and Zhu X: Improved conjunctival transplantation for corneal ulcer. Zhong Nan Da Xue Xue Bao Yi Xue Ban 35: $814-818,2010$

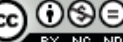

This work is licensed under a Creative Commons Attribution-NonCommercial-NoDerivatives 4.0 International (CC BY-NC-ND 4.0) License. 